\title{
Cytoplasmic maturation for activation of pig follicular oocytes cultured and arrested at metaphase I
}

\author{
K. Kikuchi ${ }^{1}$, T. Nagai ${ }^{2}$, J. Ding ${ }^{3}$, N. Yamauchi ${ }^{2 *}$, J. Noguchi ${ }^{1}$ and Y. Izaike ${ }^{1 *}$ \\ ${ }^{1}$ Department of Genetic Resources II, National Institute of Agrobiological Resources, Kannondai 2-1-2, Tsukuba, Ibaraki 305-8602, Japan; \\ ${ }^{2}$ Department of Animal Production, Tohoku National Agricultural Experiment Station, Shimokuriyagawa, Morioka, Iwate 020-0123, \\ Japan; and ${ }^{3}$ Oak Brook Fertility Center, 2425 W. 22nd Street, Suite 102, Oak Brook, IL 60523, USA
}

\begin{abstract}
A large population (62-90\%) of pig follicular oocytes can mature to metaphase II after culture for $48 \mathrm{~h}$. However, a proportion (6-22\%) remain in an immature stage at metaphase I (metaphase I-arrested). The main objective of this study was to determine whether the cytoplasm of metaphase I-arrested pig oocytes is capable of being activated by sperm penetration or parthenogenetic stimulation. After culture for $48 \mathrm{~h}$, oocytes without a polar body ( $73 \%$ were shown to be at metaphase I after staining) and those with a polar body ( $94 \%$ were at metaphase II) were fertilized in vitro. A total of $69 \%$ and $62 \%$ of the oocytes were activated to form a female pronucleus, respectively, and the rate of polar body extrusion induced by fertilization in the activated oocytes was $90 \%$ (the first polar body) and 95\% (the second polar body), respectively. When oocytes without and with a polar body were stimulated with an electric pulse, $53 \%$ and $81 \%$ of the oocytes were activated, respectively. The rate of polar body extrusion in the activated oocytes was 73\% (the first polar body) and 79\% (the second polar body), respectively. In contrast, young metaphase I oocytes cultured for $24 \mathrm{~h}$ had low $(6 \%)$ or zero activation rate after in vitro fertilization or electric pulse stimulation. However, about one-third of the young metaphase I oocytes penetrated by spermatozoa after in vitro fertilization responded to electric pulse $12 \mathrm{~h}$ after insemination, and almost all $(93 \%)$ were activated when they were stimulated $24 \mathrm{~h}$ after insemination. Patterns of polypeptide synthesis and histone $\mathrm{H} 1$ kinase activity were similar in metaphase I-arrested and metaphase II oocytes, and were characterized by increase in a $25 \mathrm{kDa}$ polypeptide and by decrease in kinase activity. Although the first step of meiotic division is impaired, these results indicate that metaphase I-arrested oocytes are mature cytoplasmically.
\end{abstract}

\section{Introduction}

Preliminary studies showed that when pig follicular oocytes are cultured for about $48 \mathrm{~h}$ and fertilized in vitro, two types of activated oocytes with a female pronucleus are observed after fixation and staining: oocytes with two polar bodies and oocytes with one polar body. Because the second polar body is extruded from an oocyte matured to metaphase II (MII) as the result of normal fertilization, activated oocytes with one polar body may be an experimental artefact or derived from activation of immature oocytes. Three possibilities have been addressed in earlier studies: (i) one polar body may be removed from the specimen during fixation and staining of oocytes; (ii) MII oocytes are activated by penetrating spermatozoa but the second polar body is not extruded; and (iii) immature oocytes, such as oocytes

*Present address: Department of Animal Reproduction, National Institute of Animal Industry, Norindanchi PO Box 5, Tsukuba, Ibaraki 305-0901, Japan. Received 4 August 1998. arrested at metaphase I (MI) (MI-arrested oocytes), are activated by sperm penetration and emit the first polar body. The last hypothesis seems most likely because, under experimental conditions, spermatozoa can penetrate immature oocytes from the germinal vesicle (GV) stage to MII in mice (Iwamatsu and Chang, 1972), hamsters (Barros and Munoz, 1974), rabbits (Overstreet and Bedford, 1974), rats (Niwa and Chang, 1975), dogs (Mahi and Yanagimachi, 1976), cows (Niwa et al., 1991), pigs (Wang et al., 1994) and humans (Overstreet and Hembree, 1976; Overstreet et al., 1980). The penetrated immature oocytes that undergo germinal vesicle breakdown (GVBD) can be activated and form a female pronucleus in rats (Niwa and Chang, 1975), hamsters (Usui and Yanagimachi, 1976) and cows (Chian et al., 1992; Abeydeera et al., 1994). The objectives of the present study were: (i) to confirm the existence of fertilized oocytes with one polar body by direct staining with a fluorescent dye; (ii) to investigate whether the cytoplasm of MI-arrested oocytes is capable of forming a female pronucleus after sperm penetration or parthenogenetic stimulation by electric 
pulse; and (iii) to compare the maturity of oocyte cytoplasm in MI and MII oocytes by analysis of polypeptide synthesis and histone $\mathrm{H} 1$ kinase activity.

\section{Materials and Methods}

\section{Collection of pig follicular oocytes}

Pig follicular oocytes were collected as described by Kikuchi et al. (1993). Ovaries were obtained at a local abattoir and transported at $35^{\circ} \mathrm{C}$ to the laboratory. The ovaries were washed in PBS (Nissui Pharmaceutical Co. Ltd, Tokyo) and placed in medium 199 (with Hanks' salts; Gibco, Life Technologies Inc., Grand Island, NY) supplemented with $10 \%(\mathrm{v} / \mathrm{v})$ fetal bovine serum (FBS; Gibco), 20 mmol Hepes $\mathrm{l}^{-1}$ (Dojindo Laboratories, Kumamoto), $100 \mathrm{iu}$ penicillin $\mathrm{G}$ potassium $\mathrm{ml}^{-1}$ (Sigma Chemical Co., St Louis, MO) and $0.1 \mathrm{mg}$ streptomycin sulfate $\mathrm{ml}^{-1}$ (Sigma). Follicles $3-6 \mathrm{~mm}$ in diameter were punctured with a surgical blade and cumulus-oocyte complexes were collected.

\section{Experiment 1: nuclear changes using different maturation systems}

Two culture systems were used for oocyte maturation to obtain a large number of immature oocytes or to compare the behaviour of penetrated sperm heads with that reported in other species. In the first system, approximately 50 cumulusoocyte complexes were cultured in $35 \mathrm{~mm}$ plastic dishes (Falcon No. 1008, Becton Dickinson and Company, Lincoln Park, NJ) containing $2 \mathrm{ml}$ culture medium consisting of medium 199 (with Earle's salts; Gibco) supplemented with $10 \% \mathrm{FBS}$ and gonadotrophin (NIH-LH-022, $2.5 \mu \mathrm{g} \mathrm{ml}^{-1}$; NIHFSH-P2, $2.5 \mu \mathrm{g} \mathrm{ml}^{-1}$ ) (m-M199) (Kikuchi et al., 1993). Parietal granulosa cells $\left(5 \times 10^{6}\right.$ cells $\mathrm{ml}^{-1}$, dispersed from the follicular wall) and two everted theca shells were also included. The cumulus-oocyte complexes were cultured at $39^{\circ} \mathrm{C}$ under $5 \% \mathrm{CO}_{2}$ in air on a mechanical platform with gentle agitation (Nagai et al., 1993). In some experiments, Waymouth MB 752/1 medium (Gibco) supplemented with $10 \%$ FBS, $10 \%(\mathrm{v} / \mathrm{v})$ pig follicular fluid, $2.5 \mu \mathrm{g} \mathrm{FSH} \mathrm{ml}$ (Antrin, Denka Pharmaceutical Co. Ltd, Kanagawa) and antibiotics (penicillin $G$ potassium and streptomycin sulfate) was used as the culture medium (m-Waymouth) (Kikuchi et al., 1995a). About ten cumulus-oocyte complexes were cultured in $100 \mu \mathrm{l}$ maturation medium covered with mineral oil (E. R. Squibb \& Sons Inc., Princeton, NJ) in $35 \mathrm{~mm}$ plastic dishes at $39^{\circ} \mathrm{C}$ under $5 \% \mathrm{CO}_{2}$ in air. Some of the oocytes cultured from 24 to $48 \mathrm{~h}$ were fixed in acetic alcohol (1:3) for 2-3 days, stained with $1 \%(\mathrm{w} / \mathrm{v})$ aceto-orcein solution and examined for nuclear status under a phase contrast microscope to confirm the nuclear changes during culture in both media. Four replicated trials were performed in this experiment.

\section{Experiment 2: confirmation of accuracy of whole mount preparation after fixation and staining}

The presence of polar bodies in oocytes after in vitro fertilization (IVF) was determined by fluorescent DNA staining of the live oocytes before examination to confirm that the polar bodies could not be removed by fixation with acetic alcohol and staining with aceto-orcein.

IVF of cultured oocytes. After culture in m-M199 for $48 \mathrm{~h}$, IVF was carried out as described by Kikuchi et al. (1993). Bracket and Oliphant solution (1975) modified with $10 \mathrm{mg}$ BSA ml $l^{-1}$ (Fraction V, Sigma) and $2 \mathrm{mmol}$ anhydro-caffeine $\mathrm{l}^{-1}$ (Sigma) was used as fertilization medium. Frozen epididymal spermatozoa (Kikuchi et al., 1998) from a Large White boar were thawed and preincubated for $1 \mathrm{~h}$ at $37^{\circ} \mathrm{C}$ under $5 \% \mathrm{CO}_{2}$ in air in a $35 \mathrm{~mm}$ plastic dish containing $0.25 \mathrm{ml}$ medium 199 (with Earle's salts) adjusted to pH 7.8 with $0.1 \mathrm{~mol} \mathrm{NaOH} \mathrm{l}{ }^{-1}$ after supplementation with $2.9 \mathrm{mmol}$ calcium lactate $1^{-1}$, 3.1 mmol glucose $1^{-1}, 25 \mathrm{mmol}$ Hepes $1^{-1}$ and $10 \%$ FBS (Nagai et al., 1988). The concentration of spermatozoa during preincubation was $2.5 \times 10^{8}$ cells $\mathrm{ml}^{-1}$. A proportion of the preincubated spermatozoa was introduced into $100 \mu \mathrm{l}$ fertilization medium containing about 20 cumulus-oocyte complexes so that the final sperm concentration at fertilization was $1.0 \times 10^{6}$ cells $\mathrm{ml}^{-1}$. Cumulus-oocyte complexes were coincubated with spermatozoa for $6 \mathrm{~h}$ and were then transferred to Brinster's medium for ovum culture II solution (BMOC-II; Brinster, 1965) containing $4 \mathrm{mg} \mathrm{BSA} \mathrm{ml}^{-1}$ and cultured for $4 \mathrm{~h}$.

Staining with a fluorescent dye and aceto-orcein solution. Inseminated and cultured oocytes were mounted on a glass slide and covered with a cover slip (whole mount preparation). PBS containing $10 \mu \mathrm{mol} 4^{\prime}$,6-diamidino-2-phenylindole $\mathrm{I}^{-1}$ (DAPI, Sigma) was introduced into the space between the glass slide and the cover slip, and oocytes were examined under a fluorescence microscope. This staining method allows the nuclear status of oocytes and penetrated spermatozoa, and the condition of polar bodies in the perivitelline space to be observed. The preparations were immediately transferred into acetic alcohol and fixed, and were then stained and examined for nuclear status as described earlier. Four replicated trials were performed in this experiment.

\section{Experiment 3: IVF and artificial stimulation of immature and mature oocytes}

Cultured oocytes were divided into immature and mature groups and were then fertilized in vitro or stimulated by an electric pulse to investigate whether both MI and MII oocytes respond to the stimuli of sperm penetration or parthenogenetic stimulation.

Classification of immature and mature oocytes. After culture in m-Waymouth for 24 or $48 \mathrm{~h}$, oocytes were denuded using $150 \mathrm{iu}$ hyaluronidase (Sigma) $\mathrm{ml}^{-1}$ and gentle pipetting. Denuded oocytes were transferred to medium 199 with Hank's salts (described earlier) and then immature and mature oocytes, classified as those without (PB-) or with $(\mathrm{PB}+)$ the first polar body, respectively, were collected under a Nomarski differential interference contrast microscope (Kikuchi et al., 1995a). Some of the classified oocytes were fixed, stained and examined to determine the efficacy of this classification. The remaining oocytes were used in the 
experiments involving IVF or parthenogenetic stimulation. Three replicated trials were performed in this experiment.

IVF of classified oocytes. After culture for 24 or $48 \mathrm{~h}$, oocytes were classified as $\mathrm{PB}-$ or $\mathrm{PB}+$. A proportion of these oocytes was inseminated and cultured before fixation as described for Expt 2. Non-inseminated oocytes were used as a control. Nuclear status was examined after fixation and staining. Three replicated trials were performed in this experiment.

Parthenogenetic stimulation of classified oocytes. Oocytes classified as $\mathrm{PB}$ - and $\mathrm{PB}+$ were subjected to parthenogenetic activation. Oocytes were washed three times in the activation solution consisting of $0.3 \mathrm{~mol}$ D-mannitol $\mathrm{l}^{-1}$ (Wako Pure Chemical, Tokyo), $0.1 \mathrm{mmol} \mathrm{CaCl}_{2} \cdot 2 \mathrm{H}_{2} \mathrm{O} \mathrm{\mathbf {l } ^ { - 1 }}, 0.1 \mathrm{mmol}$ $\mathrm{MgCl}_{2} \cdot 2 \mathrm{H}_{2} \mathrm{Ol}^{-1}$ and $0.2 \mathrm{mg} \mathrm{BSA} \mathrm{ml}^{-1}$. The oocytes were then transferred to the hybridizing chamber (FTC-22W, Shimadzu Corporation, Tokyo) containing $50 \mu \mathrm{l}$ activation solution, and stimulated with a $20 \mu$ s pulse at $1.5 \mathrm{kV} \mathrm{DC} \mathrm{cm}^{-1}$ using a somatic hybridizer (SSH-10, Shimadzu). Non-stimulated oocytes were used as a control. Stimulated and non-stimulated oocytes were transferred to BMOC-II solution and cultured for $10 \mathrm{~h}$. Oocytes were then fixed, stained and examined for nuclear status. Three replicated trials were performed in this experiment.

\section{Experiment 4: culture of immature oocytes after IVF and response to electric stimulation.}

The behaviour of sperm nuclei incorporated into the cytoplasm of young MI oocytes and the ability of oocyte cytoplasm to be activated after parthenogenetic stimulation were examined to clarify the differences in the cytoplasm of young MI oocytes and MI-arrested or MII oocytes.

Culture of immature oocytes fertilized in vitro after $24 \mathrm{~h}$ culture in maturation medium. After culture for $24 \mathrm{~h}$ in m-M199, cumulusoocyte complexes were inseminated with preincubated boar spermatozoa. After $6 \mathrm{~h}$ co-incubation with spermatozoa, some of the oocytes were immediately fixed $(6 \mathrm{~h}$ after insemination), and the others were cultured in BMOC-II solution for $6,12,18,24$ and $30 \mathrm{~h}$ and were then fixed $(12,18,24,30$ and $36 \mathrm{~h}$ after insemination, respectively). Nuclear status was examined after staining.

Artificial stimulation of immature IVF oocytes. After IVF and subsequent culture, the oocytes were subjected to an electrical pulse 12 and $24 \mathrm{~h}$ after insemination, as described in Expt 3. The oocytes were then incubated in BMOC-II solution for $12 \mathrm{~h}$ before fixation and staining for examination of nuclear status. Three replicated trials were performed in this experiment.

\section{Experiment 5: examination of polypeptide synthesis and histone H1 kinase activity}

Cytoplasmic indices such as polypeptide synthesis and histone $\mathrm{H} 1$ kinase activity in oocytes were evaluated to compare the cytoplasm of MI (24 h), MI-arrested (48 h) and MII (48 h) oocytes.

Fluorography of $\left[{ }^{35} S\right]$ polypeptides synthesized during oocyte culture. After culture in m-M199 for 24 or $48 \mathrm{~h}$, cumulusoocyte complexes were labelled with $\left[{ }^{35} \mathrm{~S}\right]$ methionine and classified according to their nuclear status after staining with DAPI before preparation for electrophoresis and autoradiography (Ding et al., 1992a,b). Briefly, cumulus-oocyte complexes were incubated in labelling solution containing [ $\left.{ }^{35} \mathrm{~S}\right]$ methionine at a final concentration of $1.85 \times 10^{7} \mathrm{~Bq} \mathrm{ml}^{-1}$ (Amersham) for $3 \mathrm{~h}$ at $39^{\circ} \mathrm{C}$ (see Moor et al., 1981). The cumulus-oocyte complexes were then washed in $\left[{ }^{35} \mathrm{~S}\right]$ methionine-free labelling medium and cultured transiently (15 to $20 \mathrm{~min}$ ) in medium containing $10 \mu \mathrm{mol}$ DAPI $\mathrm{l}^{-1}$. Cumulus cells were then removed from the oocytes and nuclear status was determined under a fluorescence microscope. Oocytes were recovered individually and placed in groups according to their nuclear configurations. A group of 1-3 oocytes of the same configuration was washed briefly in a solution of $10 \mathrm{mmol}$ Tris $1^{-1}$ and $0.1 \mathrm{mmol}$ EDTA $1^{-1}$, transferred in a small volume $(<4 \mu \mathrm{l})$ of this solution to a $0.5 \mathrm{ml}$ microtube, lyophilized, and stored at $-70^{\circ} \mathrm{C}$ until required for gel electrophoresis. Oocytes were prepared for protein analysis and polypeptides were separated using $8-15 \%$ linear gradient SDS-PAGE (Moor et al., 1981).

Histone H1 kinase activity. After culture in m-Waymouth for 24 and $48 \mathrm{~h}$, oocytes were denuded by hyaluronidase treatment, stained with DAPI and classified as GV, MI or MII stage under a fluorescence microscope (Kikuchi et al., 1995b). The oocytes were washed three times in the assay solution consisting of $60 \mathrm{mmol} \beta$-glycero phosphate $\mathrm{l}^{-1}, 30 \mathrm{mmol}$ p-nitro-phenyl phosphate $1^{-1}, 25 \mathrm{mmol}$ Mops $1^{-1}$ ( $\mathrm{pH} 7.2$ ),

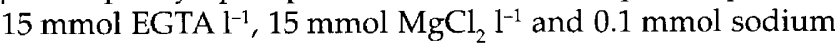
vanadate $1^{-1}$ (Wako) for the assay of histone $\mathrm{H} 1$ kinase activity (Naito and Toyoda, 1991). Ten oocytes were placed separately into plastic tubes containing $5 \mu \mathrm{l}$ solution, frozen at $-70^{\circ} \mathrm{C}$ to break the oocyte membrane and stored at the same temperature until the assay was performed. The histone $\mathrm{H} 1$ kinase assay was carried out as described by Dominko and First (1996). The reaction mixture contained $5 \mu \mathrm{l}$ of the sample solution, which was thawed in a solution containing $1 \mu \mathrm{l}$ of $1.0 \mathrm{mg}$ histone $\mathrm{H}_{1} \mathrm{ml}^{-1}$ (Sigma), $1 \mu \mathrm{l}$ $\left[\gamma^{32} \mathrm{P}\right]$ ATP $\left(3.7 \times 10^{8} \mathrm{~Bq} \mathrm{\textrm {ml } ^ { - 1 }}\right.$, Amersham $), 5 \mu \mathrm{l}$ kinase buffer (containing $80 \mathrm{mmol} \beta$-glycero phosphate $\mathrm{l}^{-1}, 20 \mathrm{mmol}$ ethylene glycol-bis ( $\beta$-aminoethyl ether) $N, N, N^{\prime}, N^{\prime}$-tetraacetic acid $\mathrm{l}^{-1}, 15 \mathrm{mmol} \mathrm{MgCl}_{2} \mathrm{l}^{-1}$ and $1 \mathrm{mmol}$ dithiothreitol $\left.1^{-1}\right)$ and protein kinase inhibitors $(1 \mathrm{mmol}$ sodium ortho vanadate $\mathrm{l}^{-1}, 10 \mu \mathrm{g}$ aprotinin $\mathrm{ml}^{-1}$ and $10 \mu \mathrm{g}$ pepstain $\mathrm{A} \mathrm{ml}^{-1}$ ) at room temperature just before the assay. The mixture was incubated for $30 \mathrm{~min}$ at room temperature. The reaction was stopped by the addition of $10 \mu \mathrm{l}$ of $2 \times$ electrophoresis sample buffer containing $100 \mathrm{mmol}$ dithiothreitol $\mathrm{ml}^{-1}$. The mixture was then subjected to $10 \%$ SDS-PAGE (Laemmli, 1970), and phosphorylated histone bands were visualized after autoradiography. The intensity of the bands was analysed using an image densitometer (Bio-Rad, Model GS-700). Three replicated trials were performed in this experiment. 
Table 1. Nuclear status in pig oocytes after culture for $24-48 \mathrm{~h}$ in m-M199 or m-Waymouth medium

\begin{tabular}{|c|c|c|c|c|c|c|c|c|}
\hline Medium & Culture (h) & $\begin{array}{c}\text { Number of } \\
\text { oocytes } \\
\text { examined }\end{array}$ & \multicolumn{6}{|c|}{ Number of oocytes at } \\
\hline m-M199 & 24 & 57 & $3(5 \pm 3)^{a b}$ & $25(44 \pm 21)^{a}$ & $28(49 \pm 20)^{\mathrm{ab}}$ & $0(0 \pm 0)^{\mathrm{a}}$ & $0(0 \pm 0)^{\mathrm{a}}$ & $1(2 \pm 1)$ \\
\hline m-M199 & 30 & 74 & $7(9 \pm 3)^{\mathrm{ac}}$ & $6(8 \pm 5)^{b}$ & $41(55 \pm 14)^{a}$ & $9(12 \pm 8)^{\mathrm{b}}$ & $9(12 \pm 9)^{a}$ & $2(3 \pm 3)$ \\
\hline m-M199 & 36 & 57 & $1(2 \pm 3)^{a b}$ & $0(0 \pm 0)^{\mathrm{b}}$ & $9(16 \pm 4)^{\mathrm{c}}$ & $0(0 \pm 0)^{a}$ & $46(81 \pm 3)^{\mathrm{bc}}$ & $1(2 \pm 3)$ \\
\hline m-Waymouth & 24 & 69 & $12(17 \pm 3)^{c}$ & $10(15 \pm 7)^{\mathrm{b}}$ & $42(61 \pm 5)^{\mathrm{a}}$ & $0(0 \pm 0)^{a}$ & $0(0 \pm 0)^{\mathrm{a}}$ & $5(7 \pm 5)$ \\
\hline m-Waymouth & 30 & 113 & $10(9 \pm 1)^{a}$ & $4(3 \pm 2)^{\mathrm{b}}$ & $76(67 \pm 3)^{a}$ & $11(10 \pm 5)^{\mathrm{ab}}$ & $7(6 \pm 5)^{a}$ & $5(4 \pm 3)$ \\
\hline m-Waymouth & 36 & 123 & $8(7 \pm 3)^{a}$ & $2(2 \pm 1)^{b}$ & $31(25 \pm 2)^{\mathrm{bc}}$ & $21(17 \pm 8)^{\mathrm{ab}}$ & $59(48 \pm 5)^{\mathrm{e}}$ & $2(2 \pm 2)$ \\
\hline m-Waymouth & 42 & 103 & $6(6 \pm 1)^{a b}$ & $0(0 \pm 0)^{\mathrm{b}}$ & $22(21 \pm 2)^{\mathrm{bc}}$ & $6(6 \pm 3)^{\mathrm{ab}}$ & $62(60 \pm 0)^{e}$ & $7(7 \pm 5)$ \\
\hline m-Waymouth & 48 & 126 & $9(7 \pm 2)^{\mathrm{ab}}$ & $1(1 \pm 1)^{\mathrm{b}}$ & $28(22 \pm 2)^{\mathrm{bc}}$ & $6(5 \pm 3)^{a b}$ & $78(62 \pm 2)^{\mathrm{ce}}$ & $4(3 \pm 3)$ \\
\hline
\end{tabular}

Percentages are expressed as mean \pm SEM.

${ }^{a}-$ Within columns percentages with different superscripts are significantly different by Duncan's multiple range test $(P<0.05)$.

Table 2. Pig follicular oocytes fertilized in vitro and stained with DAPI and aceto-orcein

\begin{tabular}{|c|c|c|c|c|c|c|c|c|c|c|}
\hline \multirow{2}{*}{$\begin{array}{l}\text { Oocyte } \\
\text { examination }\end{array}$} & \multirow{2}{*}{$\begin{array}{l}\text { Number of } \\
\text { oocytes } \\
\text { examined }\end{array}$} & \multirow{2}{*}{$\begin{array}{c}\text { Percentage of } \\
\text { maturing } \\
\text { oocytes }^{\mathrm{a}}\end{array}$} & \multirow{2}{*}{$\begin{array}{l}\text { Percentage of } \\
\text { penetrated } \\
\text { oocytes }\end{array}$} & & \multicolumn{6}{|c|}{ Percentage of activated oocytes ${ }^{b}$} \\
\hline & & & & Total & Total & $\mathrm{En}^{c}$ & $\mathrm{MPN}^{\mathrm{c}}$ & Total & $\mathrm{En}^{\mathrm{c}}$ & MPNc \\
\hline DAPI & 122 & $\begin{array}{c}121 \\
(99 \pm 1)\end{array}$ & $\begin{array}{c}90 \\
(74 \pm 4)\end{array}$ & $\begin{array}{c}85 \\
(70 \pm 3)\end{array}$ & $\begin{array}{c}20 \\
(16 \pm 4)\end{array}$ & $\begin{array}{c}12 \\
(10 \pm 3)\end{array}$ & $\begin{array}{c}8 \\
(7 \pm 2)\end{array}$ & $\begin{array}{c}65 \\
(53 \pm 6)\end{array}$ & $\begin{array}{c}31 \\
(25 \pm 8)\end{array}$ & $\begin{array}{c}34 \\
(28 \pm 7)\end{array}$ \\
\hline Aceto-orcein & 122 & $\begin{array}{c}121 \\
(99 \pm 1)\end{array}$ & $\begin{array}{c}90 \\
(74 \pm 4)\end{array}$ & $\begin{array}{c}85 \\
(70 \pm 3)\end{array}$ & $\begin{array}{c}20 \\
(16 \pm 4)\end{array}$ & $\begin{array}{c}11 \\
(9 \pm 2)\end{array}$ & $\begin{array}{c}9 \\
(7 \pm 3)\end{array}$ & $\begin{array}{c}65 \\
(53 \pm 6)\end{array}$ & $\begin{array}{c}25 \\
(21 \pm 7)\end{array}$ & $\begin{array}{c}40 \\
(33 \pm 7)\end{array}$ \\
\hline
\end{tabular}

Percentages are expressed as mean \pm SEM.

"Oocytes that underwent germinal vesicle breakdown.

bActivated oocytes with a female pronucleus.

'Oocytes with enlarged or swollen sperm heads (En) and at least one male pronucleus (MPN).

\section{Statistical analysis}

All data, except for the culture of immature oocytes fertilized in vitro after $24 \mathrm{~h}$ culture in maturation medium (Expt 4) and fluorography of ${ }^{35}$ S]polypeptides synthesized during oocyte culture (Expt 5), were subjected to ANOVA using general linear model procedures (SAS). Nuclear status, sperm penetration and oocyte activation were analysed by Duncan's multiple range test after transformation using arcsin of percentage (Snedecor and Cochran, 1967).

\section{Results}

\section{Experiment 1}

Nuclear status in oocytes cultured in m-M199 and mWaymouth for 24-48 h is summarized (Table 1). In both maturation media, GVBD had already started in the oocytes that were cultured for $24 \mathrm{~h}$. However, oocytes cultured in m-M199 showed a significantly higher proportion of GVBD $(P<0.05)$ earlier in the culture $(24 \mathrm{~h})$ than those cultured in $\mathrm{m}$-Waymouth. The percentage of nuclear maturation to MII in oocytes cultured in m-M199 for 36-48 h was significantly higher $(P<0.05)$ than that in oocytes cultured in $m$-Waymouth. However, a proportion of cultured oocytes remained at immature stages such as GV, GVBD and MI after culture for $48 \mathrm{~h}$. The percentage of immature oocytes was not different in oocytes cultured for $30-48 \mathrm{~h}$ in both media. A total of $2-7 \%$ degenerated oocytes was observed with the same incidence in each of the cultures.

\section{Experiment 2}

Examination after in vitro fertilization and staining with DAPI of 122 oocytes cultured in maturation medium for $48 \mathrm{~h}$ revealed that $70 \%$ of the oocytes were putatively activated and had a female pronucleus (Table 2). When those oocytes were re-examined after fixation with acetic alcohol and staining with aceto-orcein, $92 \%(78 / 85)$ of the oocytes produced results that were in agreement with DAPI staining. No difference in the number of polar bodies was observed in the two examinations. However, $8 \%(7 / 85)$ of the results were not in agreement with sperm nuclear changes. In these oocytes, male pronuclei were mistakenly identified as penetrated (enlarged or swollen) sperm heads because their morphology is similar under the fluorescence microscope. With the two methods of examination, 24\% (20/85) of the activated oocytes were found to have only one polar body (Fig. 1). 

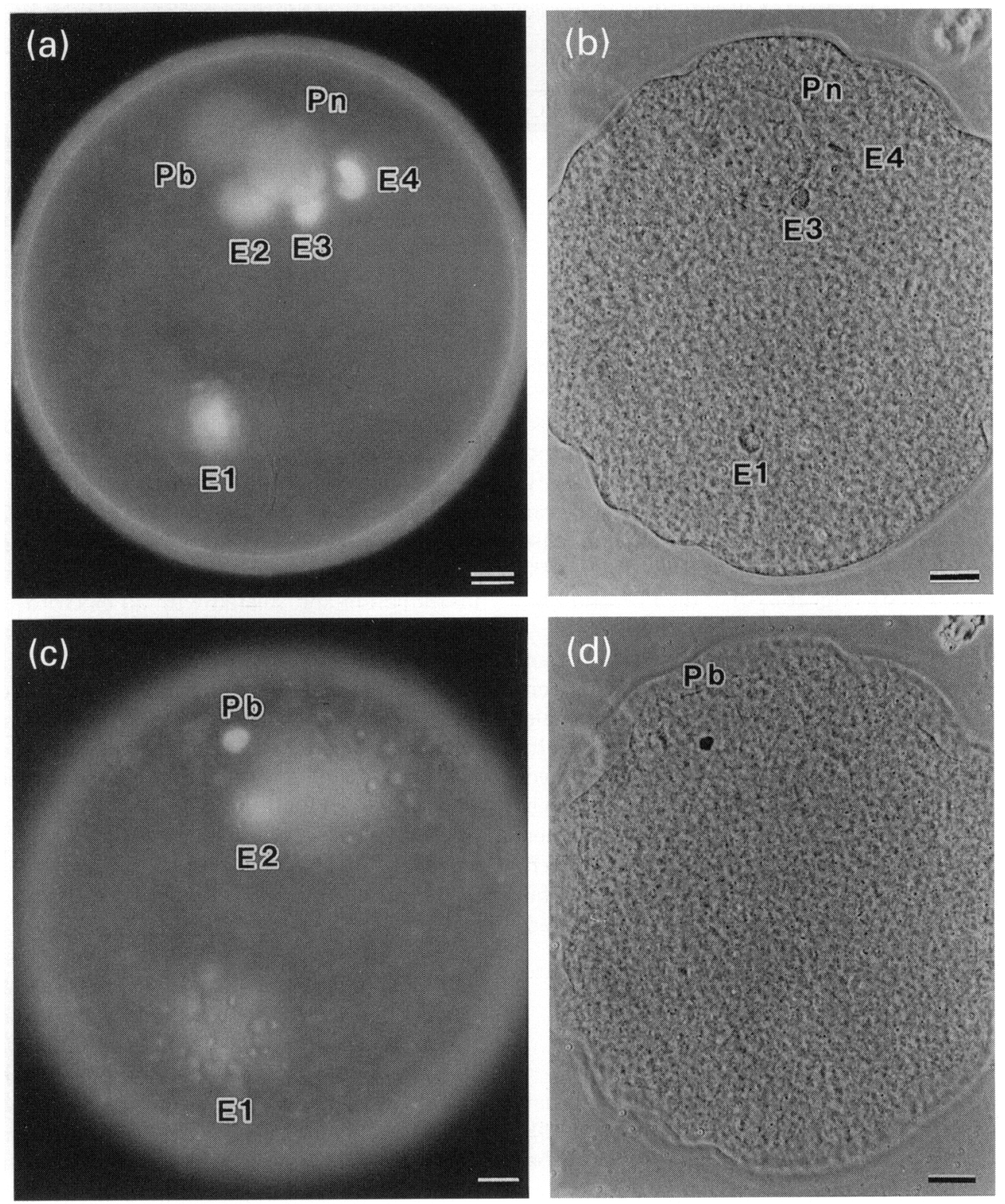

Fig. 1. Whole mount preparation of a pig oocyte fertilized in vitro. The oocyte was stained with $4^{\prime}, 6$-diamidino-2-phenylindole (DAPI) $(\mathrm{a}, \mathrm{c})$ and after examination was immediately fixed in acetic alcohol, stained with aceto-orcein and re-examined (b,d). Images $(a)$ and $(b)$ show one focal plane and (c) and (d) show a second focal plane. In this activated oocyte, a pronucleus (determined as a female pronucleus) (Pn), four penetrated or enlarged sperm heads (E1-E4) and a polar body (determined as the first polar body) $(\mathrm{Pb})$ were observed. Scale bars represent $10 \mu \mathrm{m}$.

\section{Experiment 3}

The efficacy of classification of immature or mature oocytes by observation of the first polar body is shown (Table 3). After culture for $24 \mathrm{~h}$, all oocytes were classified as PBand no $\mathrm{PB}+$ oocytes were present. Examination after fixation and staining showed that all oocytes were at an immature stage such as GV, GVBD and MI stages (16, 8 and $72 \%$, respectively). A total of 238 oocytes were examined after culture for $48 \mathrm{~h}$, and $33 \%(79 / 238)$ and $67 \%(159 / 238)$ were classified as $\mathrm{PB}-$ and $\mathrm{PB}+$, respectively. Microscopic evaluation of oocytes revealed that $78 \%(62 / 79)$ of $\mathrm{PB}-$ oocytes and $3 \%$ $(5 / 159)$ of $\mathrm{PB}+$ oocytes were at MI, while $13 \%(10 / 79)$ of $\mathrm{PB}-$ oocytes and $94 \%(149 / 159)$ of PB+ oocytes were at MII.

The results of IVF of $\mathrm{PB}-$ and $\mathrm{PB}+$ oocytes are summarized (Table 4). After culture in maturation medium for $24 \mathrm{~h}$ and insemination, $69 \%$ of oocytes had been penetrated. However, only $9 \%(5 / 56)$ of the oocytes were activated and had formed a female pronucleus. The remaining penetrated oocytes were not activated: almost all were at MII and incorporated spermatozoa had slightly decondensed heads. After culture in maturation medium for $48 \mathrm{~h}$ and IVF, $62 \%$ of PB+ oocytes 
Table 3. Efficiency of classification of pig oocytes on the basis of the presence of a polar body

\begin{tabular}{|c|c|c|c|c|c|c|c|c|}
\hline \multirow[b]{2}{*}{ Culture (h) } & \multirow[b]{2}{*}{ Oocyte $^{a}$} & \multirow{2}{*}{$\begin{array}{c}\text { Total number } \\
\text { of oocytes } \\
\text { examined }\end{array}$} & \multicolumn{6}{|c|}{ Percentage of oocytes at the stage of } \\
\hline & & & Germinal vesicle & $\begin{array}{c}\text { Germinal vesicle } \\
\text { breakdown }\end{array}$ & Metaphase I & $\begin{array}{l}\text { Anaphase/ } \\
\text { Telophase I }\end{array}$ & Metaphase II & Degenerated \\
\hline $24^{\mathrm{b}}$ & PB- & 160 & $25(16 \pm 2)^{c}$ & $13(8 \pm 1)^{c}$ & $115(72 \pm 6)^{c}$ & $0(0 \pm 0)$ & $0(0 \pm 0)^{c}$ & $7(4 \pm 4)$ \\
\hline 48 & $\mathrm{~PB}-$ & 79 & $7(9 \pm 2)^{d}$ & $0(0 \pm 0)^{d}$ & $62(78 \pm 3)^{c}$ & $0(0 \pm 0)$ & $10(13 \pm 6)^{c}$ & $4(5 \pm 2)$ \\
\hline 48 & $\mathrm{~PB}+$ & 159 & $4(3 \pm 2)^{d}$ & $0(0 \pm 0)^{\mathrm{d}}$ & $5(3 \pm 2)^{d}$ & $0(0 \pm 0)$ & $149(94 \pm 4)^{\mathrm{d}}$ & $1(1 \pm 1)$ \\
\hline
\end{tabular}

Percentages are expressed as mean \pm SEM.

acultured oocytes were denuded and classified as PB- (no polar bodies) or PB+ (with the first polar body).

${ }^{b}$ After culture for $24 \mathrm{~h}$, all oocytes were classified as PB-, no PB+ oocytes were present.

'Within columns percentages with different superscripts are significantly different by Duncan's multiple range test $(P<0.05)$.

had been penetrated, of which all were activated and had formed a female pronucleus, and $95 \%$ had both first and second polar bodies (Fig. 2a). Most of the first polar body contained scattered chromatin, while in the second polar body condensed chromatin was observed. Of the PBoocytes, $69 \%$ were penetrated and all were activated, and $90 \%$ emitted only one polar body (Fig. 2b). All of the PB+ and PBoocytes cultured without spermatozoa were not activated.

The results of artificial stimulation of oocytes with an electric pulse are shown (Table 5). PB- oocytes that had been cultured for $24 \mathrm{~h}$ were not activated to form a female pronucleus when stimulated with an electric pulse. In contrast, in oocytes cultured for $48 \mathrm{~h}$ and stimulated artificially, $53 \%$ of PB- oocytes were activated, $73 \%$ of which emitted a first polar body, and a significantly higher percentage $(81 \%)$ of $\mathrm{PB}+$ oocytes were activated, of which $79 \%$ emitted both first and second polar bodies. The morphology of the polar bodies in both types of activated oocyte was similar to those of IVF oocytes.

\section{Experiment 4}

The results of IVF and culture of immature oocytes that had been cultured previously for $24 \mathrm{~h}$ are shown (Table 6). The percentage of oocytes penetrated by spermatozoa was $88 \%(275 / 314)$. When oocytes were fixed $6 \mathrm{~h}$ after insemination, $77 \%$ of the penetrated oocytes were still at MI and heads of penetrating spermatozoa were still condensed (Fig. 3a). By $12 \mathrm{~h}$ after insemination, $45 \%$ of penetrated oocytes had reached MII, in which most of the sperm heads were enlarged or swollen (Fig. $3 \mathrm{~b}$ ), and $24 \%$ had been activated by penetrated spermatozoa, of which $50 \%$ contained a female pronucleus. Formation of a male pronucleus was observed in two of the five oocytes in which a female pronucleus had formed. Between 18 and $24 \mathrm{~h}$ after insemination, $65-66 \%$ of the oocytes had not been activated by penetrated spermatozoa and were arrested in MII, while 18-25\% were activated and most contained both female and male pronuclei. At $18 \mathrm{~h}$ after insemination, some of the enlarged sperm heads in the penetrated oocytes (MII) became condensed into a small mass $(50 \%)$ (Fig. $3 c, d$ ) or transformed into metaphase chromosomes (16\%) (Fig. 3e). Some of the condensed sperm heads were incorporated into the maternal metaphase plate (Fig. 3c) and others were associated with the spindle (Fig. 3d). At 24 to $36 \mathrm{~h}$ after insemination, in $3-44 \%$ of the penetrated oocytes (MII), the sperm heads had condensed to a small mass. The incidence of transformation of sperm chromatin to metaphase chromosomes in MII oocytes increased from $21 \%$ at $24 \mathrm{~h}$ after insemination to $36 \%$ at $36 \mathrm{~h}$ after insemination.

When inseminated oocytes were cultured for $12 \mathrm{~h}$ after insemination and treated with an electrical pulse, only $35 \%$ were activated and formed a female pronucleus after a further $12 \mathrm{~h}$ in culture (Table 7). However, when oocytes were stimulated at $24 \mathrm{~h}$ after insemination, most were activated $(93 \%, P<0.05)$. The percentage of male pronucleus formation in oocytes stimulated at $24 \mathrm{~h}$ after insemination was higher $(77 \%, P<0.05)$ than that in oocytes stimulated at $12 \mathrm{~h}$ after insemination (35\%).

\section{Experiment 5}

Changes in the pattern of polypeptide synthesis in pig oocytes at MI ( 24 and $48 \mathrm{~h}$ culture) and MII ( $48 \mathrm{~h}$ culture) are shown (Fig. 4). Oocytes cultured for $48 \mathrm{~h}$ were characterized by an increase in the synthesis of a $25 \mathrm{kDa}$ polypeptide irrespective of the nuclear status (MI or MII). Synthesis of $25 \mathrm{kDa}$ polypeptide in MI oocytes after $24 \mathrm{~h}$ culture was much lower compared with MI oocytes cultured for $48 \mathrm{~h}$.

Results of histone H1 kinase activity are summarized (Fig. 5). Some of the oocytes remained at the GV stage after culture for 24 or $48 \mathrm{~h}$ (Table 1). Histone H1 kinase activity in GV stage oocytes remained at basal values regardless of the duration of the culture period. Histone H1 kinase activity in oocytes at MI after culture for $24 \mathrm{~h}$ was significantly higher $(P<0.05)$ than that in oocytes cultured for $48 \mathrm{~h}$. However, histone $\mathrm{H} 1$ kinase activity in MI-arrested oocytes was significantly higher $(P<0.05)$ than that in oocytes that had matured to MII.

\section{Discussion}

In the present study, the nuclear status of oocytes was examined after maturation in two culture systems: m-M199 (non-static culture with follicle shells) and $\mathrm{m}$-Waymouth (static culture with pig follicular fluid). Expt 1 showed that the incidence of nuclear maturation to MII was higher using m-M199 (79-90\%) after culture for 36 to $48 \mathrm{~h}$ compared with $\mathrm{m}$-Waymouth (48-62\%). Although there was no difference in 


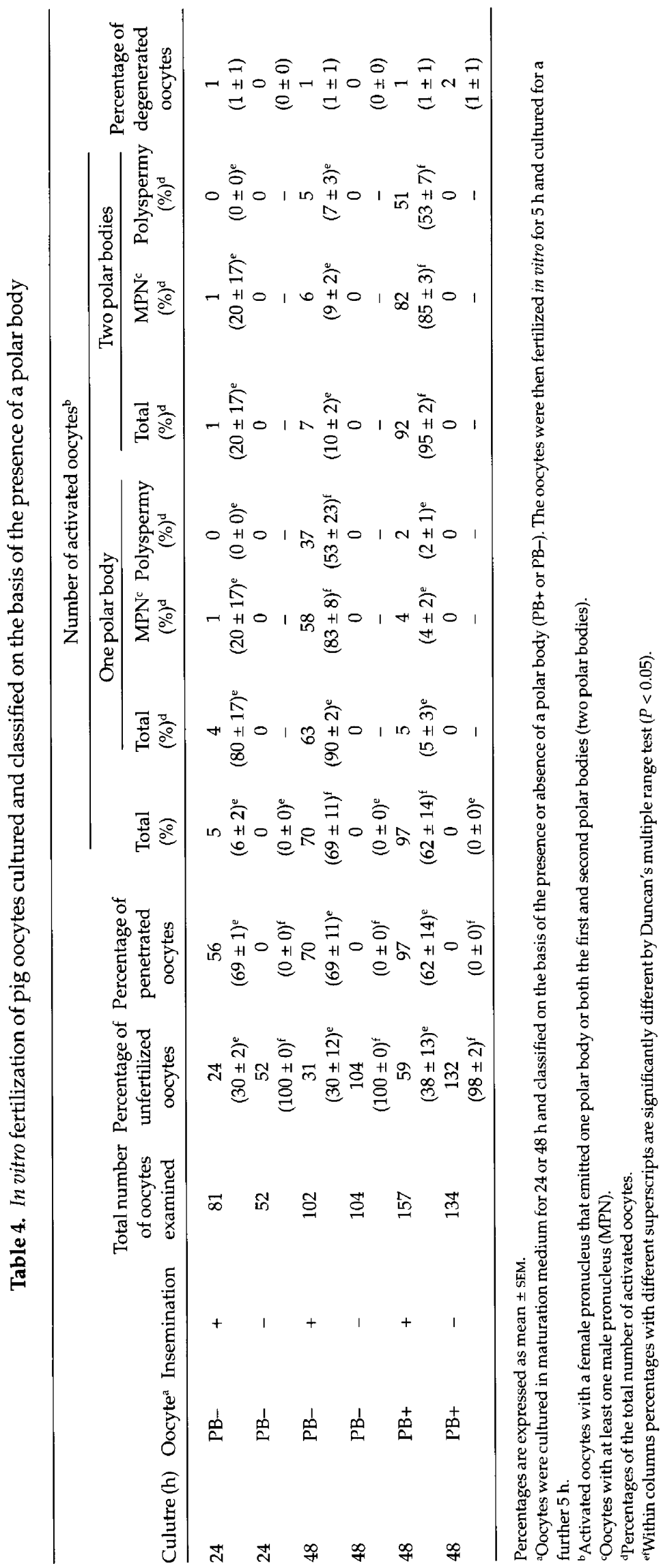



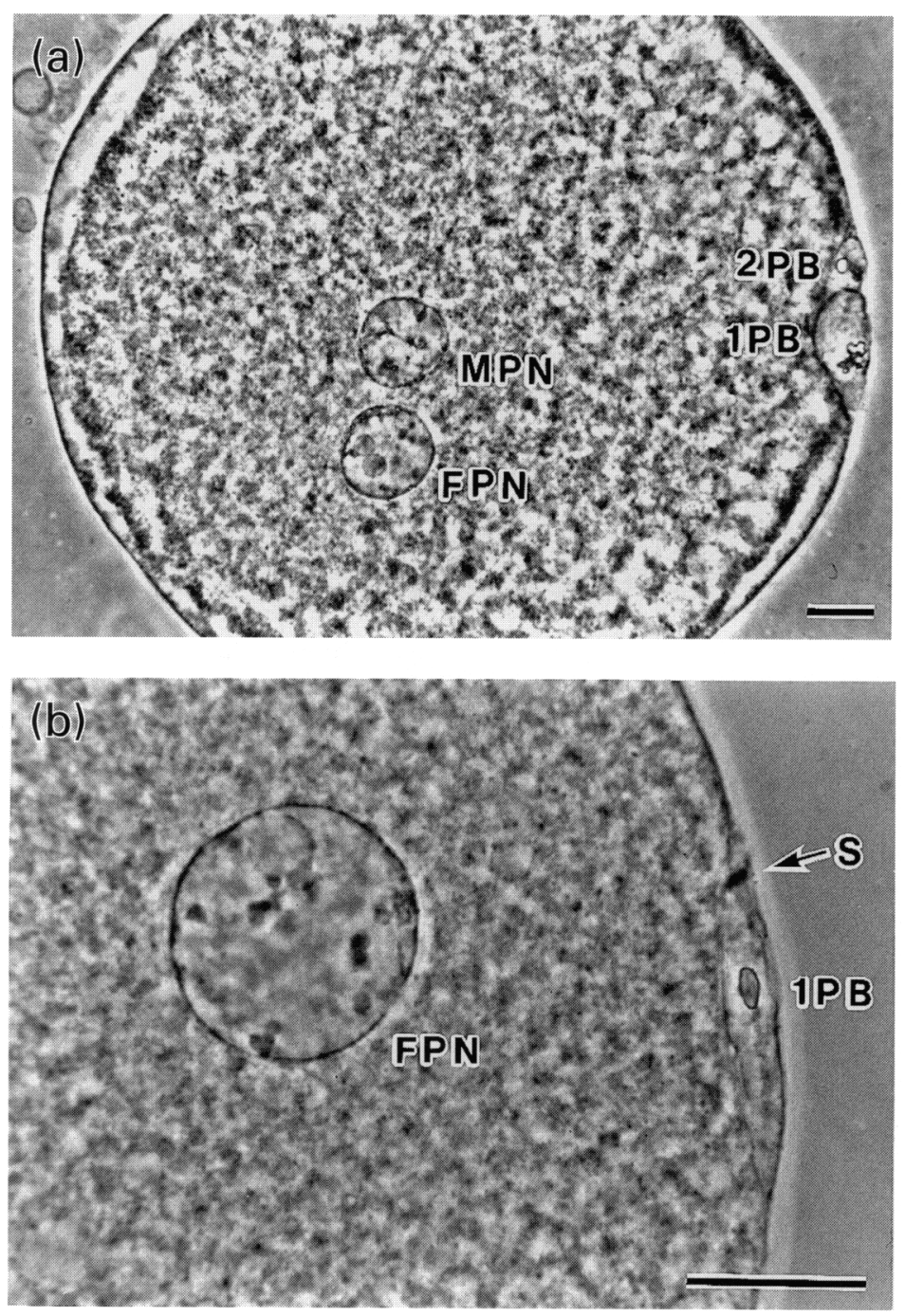

Fig. 2. Morphology of polar bodies after in vitro fertilization (IVF) of mature and immature pig oocytes cultured for $48 \mathrm{~h}$. Cultured oocytes were classified as $\mathrm{PB}+$ and $\mathrm{PB}-$ (with or without the first polar body, respectively), fertilized in vitro and examined under a phase-contrast microscope after fixation and staining with aceto-orcein. (a) Two polar bodies were observed after IVF of PB+ oocytes. The first polar body (1PB), in which the chromosome was scattered, and the second polar body (2PB), in which condensed chromatin was observed. The second polar body was recognized because of the association with the spindle (not in focus). Both single female (FPN) and male (MPN) pronuclei were observed. A sperm tail associated with the MPN is not in focus. (b) One polar body was observed after IVF of PB- oocytes. Only the first polar body $(1 \mathrm{~PB})$ associated with the spindle $(\mathrm{S})$ was observed. This polar body had condensed chromatin and was similar to that of the second polar body of $\mathrm{PB}+$ oocytes after fertilization and extrusion of two polar bodies. Scale bars represent $10 \mu \mathrm{m}$.

the percentage of immature oocytes at GV, GVBD and MI stages in the two media, there was a tendency for more oocytes to arrest at MI after culture in m-Waymouth compared with m-M199. Therefore, in some experiments in the present study, oocytes were cultured in $\mathrm{m}$-Waymouth to obtain a large number of oocytes arrested at an immature stage such as MI.

Expt 2 revealed that when non-classified oocytes cultured for $48 \mathrm{~h}$ were fertilized in vitro, two types of activated oocytes were produced: oocytes with one polar body and oocytes with two polar bodies. Examination under a fluorescence microscope after staining with DAPI enabled observation of oocyte and penetrated sperm nuclear status, and polar bodies within the perivitelline space. With this method, there is no possibility of detachment of polar bodies from oocytes during staining. The specimens were also fixed with acetic 
Table 5. Artificial activation of pig follicular oocytes classified at 24 or $48 \mathrm{~h}$ of culture on the basis of the presence of a polar body

\begin{tabular}{|c|c|c|c|c|c|c|c|c|c|}
\hline Culture (h) & Oocyte $^{\mathrm{a}}$ & Stimulation & $\begin{array}{c}\text { Total number of } \\
\text { oocytes } \\
\text { examined }\end{array}$ & $\begin{array}{l}\text { Percentage of } \\
\text { inactivated } \\
\text { oocytes }\end{array}$ & \multicolumn{4}{|c|}{ Number of activated oocytes ${ }^{b}$} & $\begin{array}{c}\text { Percentage of } \\
\text { degenerated } \\
\text { oocytes }\end{array}$ \\
\hline \multirow[t]{2}{*}{24} & PB- & + & 111 & 104 & 0 & 0 & 0 & 0 & 7 \\
\hline & & & & $(94 \pm 5)^{\mathrm{e}}$ & $(0 \pm 0)^{\mathrm{e}}$ & - & - & - & $(6 \pm 5)$ \\
\hline 24 & $\mathrm{~PB}-$ & - & 20 & 16 & 0 & 0 & 0 & 0 & 4 \\
\hline 48 & & & & $(41 \pm 5)^{f}$ & $(53 \pm 5)^{f}$ & $(73 \pm 10)^{\mathrm{e}}$ & $(14 \pm 5)^{\mathrm{e}}$ & $(14 \pm 11)$ & $(6 \pm 2)$ \\
\hline \multirow[t]{2}{*}{48} & PB- & - & 33 & 33 & 0 & 0 & 0 & 0 & 0 \\
\hline & & & & $(100 \pm 0)^{\mathrm{g}}$ & $(0 \pm 0)^{\mathrm{e}}$ & - & - & - & $(0 \pm 0)$ \\
\hline \multirow[t]{2}{*}{48} & $\mathrm{~PB}+$ & + & 154 & 28 & 124 & 11 & 98 & 15 & 2 \\
\hline & & & & $(18 \pm 5)^{\mathrm{h}}$ & $(81 \pm 5)^{\mathrm{s}}$ & $(9 \pm 3)^{\mathrm{f}}$ & $(79 \pm 7)^{f}$ & $(12 \pm 3)$ & $(1 \pm 1)$ \\
\hline 48 & $\mathrm{~PB}+$ & - & 64 & 63 & 0 & 0 & 0 & 0 & 1 \\
\hline
\end{tabular}

Percentages are expressed as mean \pm SEM.

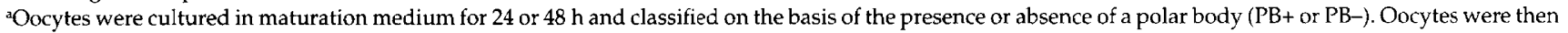
fertilized in vitro for $5 \mathrm{~h}$ and cultured for a further $5 \mathrm{~h}$.

${ }^{b}$ Activated oocytes with a female pronucleus.

"Activated oocytes with the first body (one polar body) or the first and second polar bodies (two polar bodies). Some of the activated oocytes were fragmented or lacked polar bodies (Others).

'Percentages of the total number of activated oocytes.

ehWithin columns percentages with different superscripts are significantly different by Duncan's multiple range test $(P<0.05)$.

alcohol, stained with aceto-orcein and examined under a phase-contrast microscope, the standard method for oocyte examination used in many laboratories. Almost all $(92 \%)$ of the penetrated oocytes showed extrusion of the same number of polar bodies as seen after DAPI staining. These results confirm that, after IVF of pig oocytes, activated oocytes with one polar body and a female pronucleus are not the result of fixation or staining. Therefore, the oocytes with two polar bodies are considered to be the result of normal fertilization of matured oocytes at MII. However, oocytes with one polar body may be the result of penetration of MI oocytes. Two possibilities exist for the latter: (i) an oocyte at MII is fertilized, but the second polar body is not extruded; and (ii) an oocyte arrested at MI is fertilized and the first polar body is extruded.

Cultured oocytes were classified as immature and mature and were fertilized in vitro or stimulated with an electrical pulse (Expt 3) to confirm which hypothesis is acceptable. Of those oocytes classified as PB- (without a polar body) after culture for $48 \mathrm{~h}$, $78 \%$ were MI oocytes and $13 \%$ were MII. Of those oocytes classified as PB+ (with the first polar body), $94 \%$ were MII oocytes. The $13 \%$ error rate (MII) for PB- may be the result of the difficulty of finding a polar body in the dark ooplasm, or extrusion of the polar body immediately after selection. Use of a fluorescence microscope after staining with a fluorescent dye appears to be a reliable method for observing a polar body. However, the dye itself or UV irradiation may have harmful effects on the oocyte. Therefore, this method is not suitable for oocyte classification for IVF or electric stimulation. Nevertheless, the procedure adapted in the present study had a significant effect on selection of oocytes. IVF and parthenogenesis experiments using both $\mathrm{PB}-$ and $\mathrm{PB}+$ oocytes cultured for $48 \mathrm{~h}$ confirm that MI-arrested oocytes can be activated to form a female pronucleus, as did MII oocytes when they were penetrated by spermatozoa and emitted a first polar body. These results indicate that MI-arrested oocytes have relatively mature cytoplasm and meiotic division can be resumed by stimuli such as sperm penetration or an electrical pulse, as suggested in mouse oocytes (Eppig et al., 1994; McConnell et al., 1995; Polanski, 1995). However, unlike activated MII oocytes, activated MI oocytes did not complete the second meiosis. Therefore, the genome of activated MI-arrested oocytes is maintained in the diploid state. In light of these observations, it is important to consider the ploidy of fertilized oocytes and to discuss genome size because less attention has been given to the number of polar bodies after IVF. It is also interesting that there are morphological differences in the first polar body between activated MI-arrested and MII oocytes. The appearance of the first polar body in activated MI-arrested oocytes is very similar to that of the second polar body in activated MII oocytes. The morphology of the polar bodies, especially chromatin condensation, may be controlled by the condition of ooplasm, as the extent of cytoplasmic maturation, just before extrusion of the polar body.

When immature oocytes cultured for $24 \mathrm{~h}$ were inseminated (Expt 4), spermatozoa penetrated the ooplasm and the heads of most of the penetrating spermatozoa were transformed. The sperm heads first 'enlarged' and then 'condensed' (mouse, Iwamatsu and Chang, 1972; hamster, Barros and Munoz, 1974; rabbit, Overstreet and Bedford, 1974; rat, Niwa and Chang, 1975; dog, Mahi and Yanagimachi, 1976; cow, Niwa et al., 1991; pig, Wang et al., 1992), and finally transformed to 'metaphase chromosomes' (mouse, Clarke and Masui, 1986; cow, Abeydeera and Niwa, 1992; pig, Wang and Niwa, 1997) as the subsequent culture 


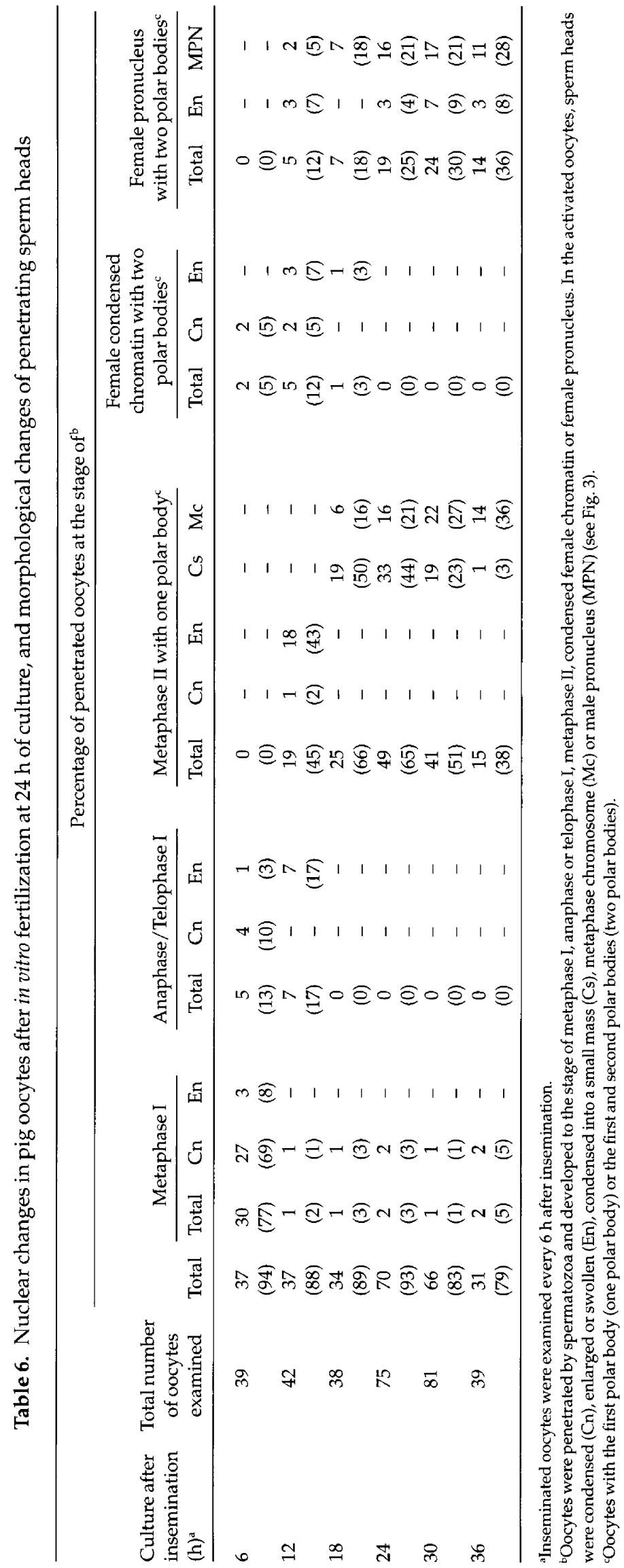



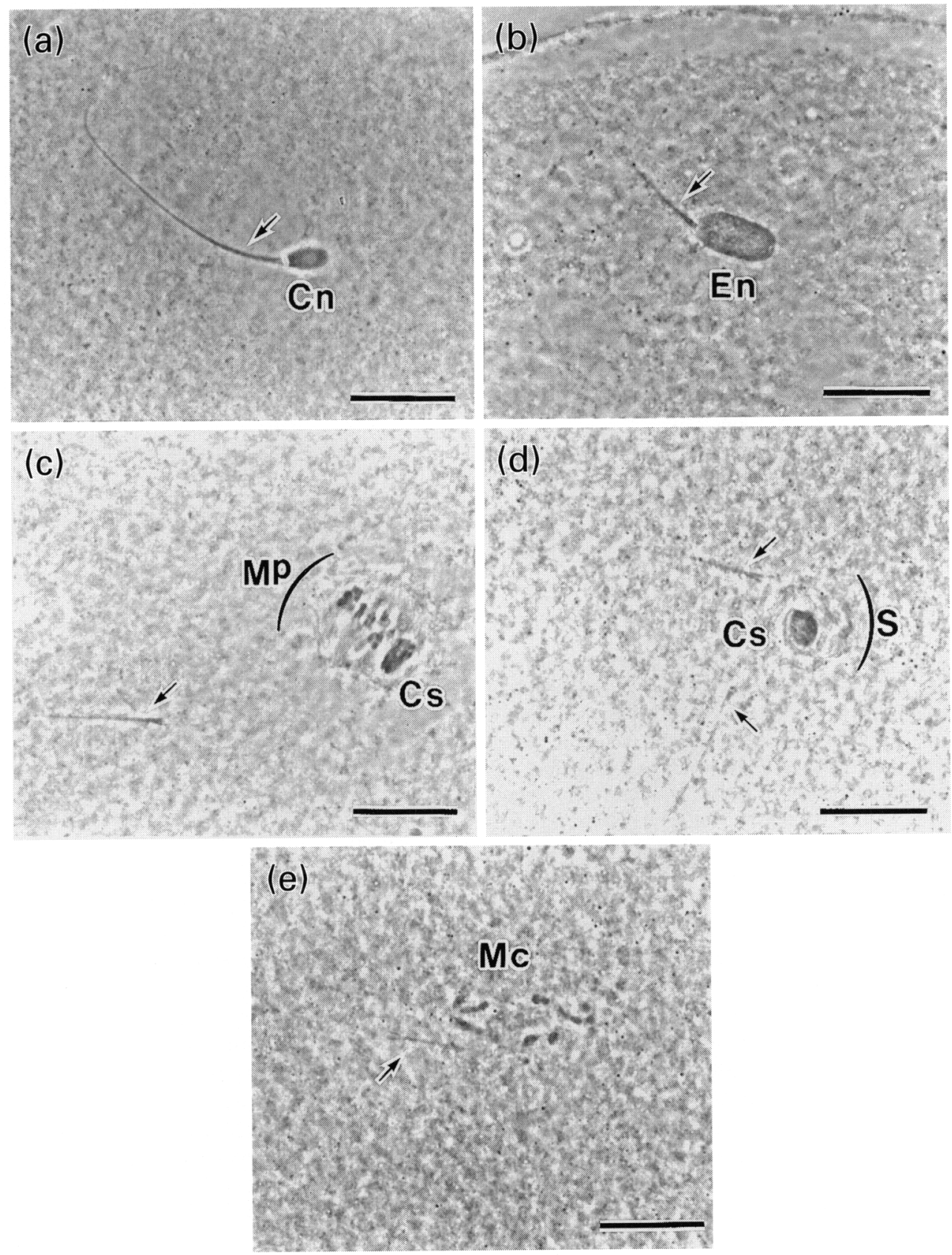

Fig. 3. Sperm heads penetrating immature (metaphase I) pig oocytes. Oocytes were cultured for $24 \mathrm{~h}$, fertilized in vitro and subsequently cultured for up to $36 \mathrm{~h}$ (see Table 6). Arrows indicate tails of the penetrating spermatozoa. Heads of penetrating spermatozoa were condensed $(\mathrm{Cn})$ at $6 \mathrm{~h}$ after insemination (a), but became enlarged or swollen (En) at $12 \mathrm{~h}$ after insemination (b). (c,d,e) At $18 \mathrm{~h}$ after insemination, some sperm heads recondensed into a small mass (Cs) or transformed into metaphase chromosomes $(\mathrm{Mc})$. Some of the recondensed heads were incorporated into the maternal metaphase plate $(\mathrm{Mp})$ and others were associated with the spindle (S). In (d) one recondensed head is visible; another is out of focus. Scale bars represent $10 \mu \mathrm{m}$.

was prolonged. Clarke and Masui (1986) reported that transformation of sperm heads to metaphase chromosomes in mouse MI oocytes is regulated by a maturation or Mphase promoting factor (MPF; Masui and Markert, 1971). In the present study, metaphase chromosomes were present in pig oocytes that had proceeded to MII, in which high MPF activity is observed (Naito and Toyoda, 1991). However, after $48 \mathrm{~h}$ culture, MI-arrested or MII oocytes form a well developed male pronucleus after sperm penetration. These results emphasize the difference in maturity of the cytoplasm between young MI oocytes and MI-arrested or MII oocytes. It is interesting that the nuclear status of penetrated 


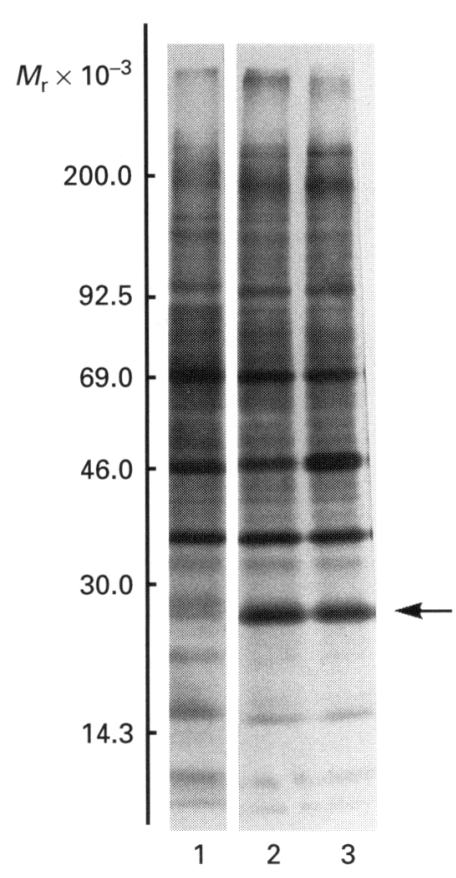

Fig. 4. Changes in the pattern of polypeptide synthesis during culture of pig oocytes. Oocytes were sampled after 24 and $48 \mathrm{~h}$ in culture and then labelled with [ $\left.{ }^{35} \mathrm{~S}\right]$ methionine for $3 \mathrm{~h}$. After labelling, the nuclear status of oocytes was examined by staining with 4',6-diamidino-2-phenylindole (DAPI) and oocytes were classified as metaphase I (MI) and metaphase II (MII). Oocytes were then subjected to SDS-PAGE. Lane 1: MI oocyte after $24 \mathrm{~h}$ culture; lane 2: MI oocyte after $48 \mathrm{~h}$ culture; lane 3 : MII oocytes after $48 \mathrm{~h}$ culture. The arrow indicates a band of $25 \mathrm{kDa}$ polypeptide in lanes 2 and 3.

immature oocytes changes from MI to MII in the same proportion as observed in non-inseminated immature oocytes. Some of the condensed sperm heads were incorporated into the oocyte metaphase plate, as if they were maternal chromosomes, or became associated with the spindle. These results indicate that young MI oocytes were not activated by sperm penetration, although some were activated spontaneously and formed both female and male pronuclei as the duration of the culture period increased. Penetrated oocytes were activated easily compared with unpenetrated oocytes cultured for the same duration. The reason for this is unclear, although the possibility that the spermatozoon contains a factor that promotes oocyte activation (Swann, 1990) must be considered. When inseminated oocytes were stimulated, the percentage of

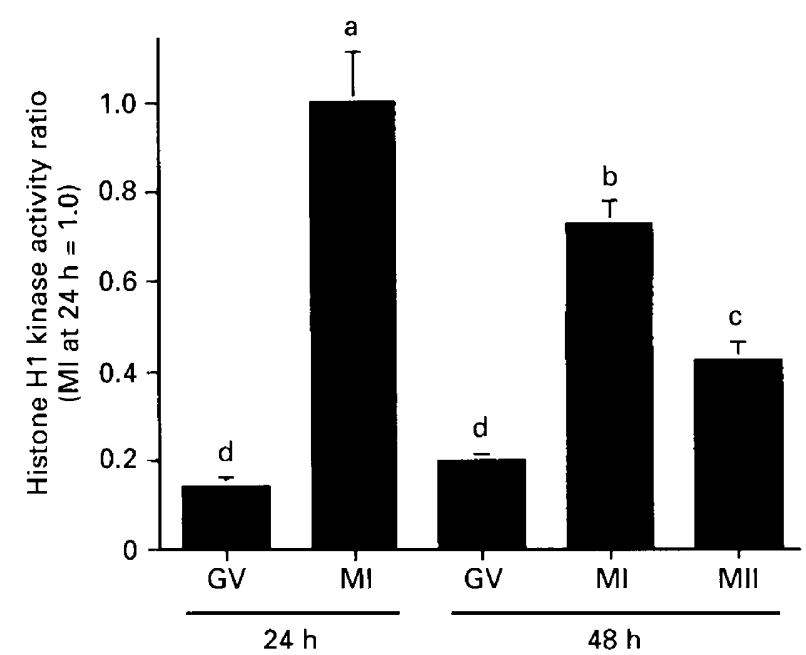

Fig. 5. Activity of histone $\mathrm{H} 1$ kinase in pig oocytes after culture for 24 or $48 \mathrm{~h}$. Oocytes at germinal vesicle stage (GV), immature oocytes at metaphase I (MI) and mature oocytes at metaphase II (MII) were identified using fluorescence microscopy. Histone $\mathrm{H} 1$ kinase activity is presented as mean \pm SEM. Bars with different letters are significantly different $(P<0.05)$.

activation (female and male pronucleus formation) was increased at $24 \mathrm{~h}$ after insemination. The ability of penetrated oocytes to be activated also seems to be enhanced as cytoplasmic maturation progresses, as occurs in oocytes cultured for $48 \mathrm{~h}$ under conditions that promote normal maturation.

Ding et al. (1992b) reported that synthesis of a $25 \mathrm{kDa}$ polypeptide increased between MI ( $28 \mathrm{~h}$ in culture) and MII $(32-47 \mathrm{~h})$. In addition, the transition of $25 \mathrm{kDa}$ protein to $22 \mathrm{kDa}$ protein is associated with oocyte activation and pronuclear formation after penetration of oocytes by spermatozoa (Ding et al., 1992a). Expt 5 revealed that the pattern of protein synthesis in MI-arrested oocytes after $48 \mathrm{~h}$ culture was similar to that in MII oocytes cultured for the same duration, and was different from that in MI oocytes cultured for $24 \mathrm{~h}$. This observation is in agreement with a report on mouse oocytes (Eppig et al., 1994). Expts 3 and 4 also confirm that cytoplasmic maturation in immature oocytes arrested at MI has already occurred and they respond to sperm penetration or parthenogenetic activation, as do oocytes at MII. These results indicate that cytoplasmic maturation of pig oocytes depends not on nuclear status but on the duration of culture. Although the function of the 25

Table 7. Activation after electrical pulse of pig oocytes cultured for $24 \mathrm{~h}$ and fertilized in vitro

\begin{tabular}{lccccc}
\hline \multirow{2}{*}{$\begin{array}{l}\text { Culture after electrical pulse } \\
\text { (h after insemination) }\end{array}$} & $\begin{array}{c}\text { Number of } \\
\text { oocytes examined }\end{array}$ & $\begin{array}{c}\text { Percentage of } \\
\text { oocytes penetrated }\end{array}$ & Total & Penetrated oocytes & With MPN $^{\mathrm{a}}$ \\
\hline 12 & 17 & $16(94 \pm 5)$ & $6(35 \pm 6)^{\mathrm{d}}$ & $6(35 \pm 6)^{\mathrm{d}}$ & $6(35 \pm 6)^{\mathrm{d}}$ \\
24 & 30 & $26(87 \pm 2)$ & $28(93 \pm 4)^{\mathrm{e}}$ & $24(80 \pm 5)^{\mathrm{e}}$ & $23(77 \pm 2)^{\mathrm{e}}$ \\
\hline
\end{tabular}

Percentages are expressed as mean \pm SEM.

Inseminated oocytes were stimulated with an electric pulse 12 or $24 \mathrm{~h}$ after insemination

${ }^{\mathrm{b}}$ Activated oocytes with a female pronucleus.

'MPN, a male pronucleus.

deWithin columns percentages with different superscripts are significantly different by Duncan's multiple range test $(P<0.05)$. 
kDa polypeptide is unclear, it appears to play an important role in cytoplasmic maturation in both MI-arrested oocytes and oocytes that have matured to MII. Funahashi et al. (1995) proposed that cytoplasmic glutathione concentration reflects the degree of cytoplasmic maturation in pig oocytes matured in vitro because it is correlated with the ability to form a male pronucleus (Yoshida, 1993). The $25 \mathrm{kDa}$ polypeptide reported here is different from glutathione, a major intercellular free thiol. In addition, the modification of the $25 \mathrm{kDa}$ polypeptide to a $22 \mathrm{kDa}$ polypeptide is a dephosphorylation process (Ding et al., 1992a). It is unclear whether there is any association between the amount of $25 \mathrm{kDa}$ polypeptide and cytoplasmic glutathione.

The mechanism of arrest at MI remains to be elucidated. Cytostatic factor (CSF), a homologue of the c-mos protooncogene product (Sagata et al., 1989), promotes MII arrest in unfertilized frog oocytes (Masui and Markert, 1971). Furthermore, Hirao and Eppig (1997) reported that c-mos participates in sustaining MI arrest in oocytes from crossbred mice (LT strain). However, the function of c-mos in pig oocytes arresting at MI has not been reported. The phenomenon of oocyte arrest appears to be similar to that induced by CSF in MII oocytes, even though in arrested oocytes the nuclear status is MI. It will be necessary to determine the relationship between physiological arrest at $\mathrm{MI}$ and the function of CSF in pig oocytes using molecular approaches in future studies.

One of the well known factors that regulates oocyte maturation is MPF, which can be measured as histone $\mathrm{H} 1$ kinase activity (Arion et al., 1988; Labbe et al., 1988a,b, 1989). Naito and Toyoda (1991) reported that during in vitro maturation of pig oocytes, histone $\mathrm{H} 1$ kinase activity is high in both MI and MII oocytes. However, in some culture media, histone H1 kinase activity is higher in MI oocytes than in MII oocytes (Naito et al., 1992). In the present study, MI oocytes cultured for $24 \mathrm{~h}$ showed higher histone $\mathrm{H} 1$ kinase activity compared with MII oocytes cultured for $48 \mathrm{~h}$, and activity in oocytes arrested at MI was intermediate. These results are in agreement with the proposal that histone H1 kinase activity is closely related to the ability of oocytes to be activated when they are matured and aged in vitro (Kikuchi et al., 1995a). A decrease in histone $\mathrm{H} 1$ kinase activity appeared to occur in both MI and MII oocytes when the culture period was extended to $48 \mathrm{~h}$. However, the extent of the decrease may vary depending on the nuclear status of oocytes. Indeed, the sensitivity to parthenogenetic stimulation of MII oocytes cultured for $48 \mathrm{~h}$ was greater $(81 \%$ activated oocytes) than that of MI-arrested oocytes (53\%), whereas no $\mathrm{MI}$ oocytes were activated after culture for $24 \mathrm{~h}$. These results indicate that a decrease in histone H1 kinase activity is also important for cytoplasmic maturation in MI-arrested oocytes and in oocytes that have matured to MII after culture in maturation medium.

In conclusion, in pig follicular oocytes cultured for a period that was long enough to produce MII oocytes, some of the oocytes arrested at MI. The MI-arrested oocytes, which were immature with regard to nuclear status, had relatively mature cytoplasm that was able to promote oocyte activation after sperm penetration or parthenogenetic stimulation. The relationship between cytoplasmic maturation and a $25 \mathrm{kDa}$ polypeptide or a decrease in histone $\mathrm{H} 1$ kinase activity in the mechanism of oocyte arrest at MI requires clarification.

The authors would like to thank H. Kaneko and A. Shimada for critical discussion and T. Aoki for technical assistance.

\section{References}

Abeydeera LR and Niwa K (1992) Ability of in vitro maturing bovine oocytes to transform sperm nuclei to metaphase chromosomes Journal of Reproduction and Fertility 96 565-572

Abeydeera LR, Okuda K and Niwa K (1994) Activation of bovine oocytes penetrated after germinal vesicle breakdown Zygote 2 273-279

Arion D, Meijer L, Breizuela L and Beach D (1988) cdc 2 is a component of the $\mathrm{M}$ phase-specific histone $\mathrm{H} 1$ kinase: evidence of identity with MPF Cell 55 371-378

Barros C and Munoz G (1974) Sperm-egg interaction in immature hamster oocytes Journal of Experimental Zoology 186 73-78

Bracket BG and Oliphant G (1975) Capacitation of rabbit spermatozoa in vitro. Biology of Reproduction 12 260-274

Brinster RL (1965) Studies on the development of mouse embryos in vitro. IV. Interaction of energy source Journal of Reproduction and Fertility $10227-240$

Chian RC, Niwa K and Nakahara H (1992) Effect of sperm penetration in vitro on completion of first meiosis by bovine oocytes arrested at various stage in culture Journal of Reproduction and Fertility $9673-78$

Clarke HJ and Masui Y (1986) Transformation of sperm nuclei to metaphase chromosomes in the cytoplasm of maturing oocytes of the mouse Journal of Cell Biology 102 1039-1046

Ding J, Clarke N, Nagai T and Moor RM (1992a) Protein and nuclear changes in pig eggs at fertilization Molecular Reproduction and Development 31 287-296

Ding J, Moor RM and Foxcroft GR (1992b) Effects of protein synthesis on maturation, sperm penetration, and pronuclear development in porcine oocytes Molecular Reproduction and Development 33 59-66

Dominko T and First NL (1996) p34cdc2 and p33CDK2 in regulation of metaphase II arrest in bovine oocytes Theriogenology 45157 (Abstract)

Eppig JJ, Shultz RM, O'Brien M and Chesnel F (1994) Relationship between the developmental programs controlling nuclear and cytoplasmic maturation of mouse oocytes Developmental Biology 164 1-9

Funahashi H, Stumpf TT, Cantley TC, Kim NH and Day BN (1995) Pronuclear formation and intracellular glutathione content of in vitromatured porcine oocytes following in vitro fertilization and/or electrical activation Zygote 3 276-281

Hirao Y and Eppig JJ (1997) Analysis of the mechanism(s) of metaphase I arrest in strain LT mouse oocytes: participation of MOS Development 124 $5107-5113$

Iwamatsu T and Chang MC (1972) Sperm penetration in vitro of mouse oocytes at various times during maturation Journal of Reproduction and Fertility 31 237-247

Kikuchi K, Nagai T, Motlik J, Shioya Y and Izaike Y (1993) Effect of follicle cells on in vitro fertilization of pig follicular oocytes Theriogenology 39 593-599

Kikuchi K, Izaike Y, Noguchi J, Furukawa T, Daen FP, Naito K and Toyoda $Y$ (1995a) Decrease of histone $\mathrm{H} 1$ kinase activity in relation to parthenogenetic activation of pig follicular oocytes matured and aged in vitro. Journal of Reproduction and Fertility $105325-330$

Kikuchi K, Naito K, Daen FP, Izaike Y and Toyoda Y (1995b) Histone H1 kinase activity during in vitro fertilization of pig follicular oocytes matured in vitro. Theriogenology 43 523-532

Kikuchi K, Nagai T, Kashiwazaki N, Ikeda H, Noguchi J, Shimada A, Soloy E and Kaneko $\mathbf{H}$ (1998) Cryopreservation and ensuing in vitro fertilization ability of boar spermatozoa from epididymides stored at $4^{\circ} \mathrm{C}$ Theriogenology 50 615-623

Labbe JC, Caponey JP, Caput D, Cavadore JC, Derancourt J, Kaghad M, Lelias JM, Picard A and Doree M (1988a) MPF from starfish oocytes at first meiotic metaphase is a heterodimer containing one molecule of cdc2 and one molecule of cyclin B EMBO journal 8 3053-3058

Labbe JC, Lee MG, Nurse P, Picard A and Doree M (1988b) Activation at Mphase of a protein kinase encoded by a starfish homologue of the cell cycle control gene cdc2+ Nature 335 251-254

Labbe JC, Picard A, Peaucellier G, Cavadore JC, Nurse P and Doree M (1989) 
Purification of MPF from starfish: identification as the $\mathrm{H} 1$ histone kinase p34cdc2 and a possible mechanism for its periodic activation Cell 57 253-263

Laemmli UK (1970) Cleavage of structural proteins during the assembly of the head of bacteriophage T4 Nature $227680-685$

McConnell JM, Campbell L and Vincent C (1995) Capacity of mouse oocytes to become activated depends on completion of cytoplasmic but not nuclear meiotic maturation Zygote 3 45-55

Mahi CA and Yanagimachi R (1976) Maturation and sperm penetration of canine ovarian oocytes in vitro. Journal of Experimental Zoology 196 189-196

Masui Y and Markert C (1971) Cytoplasmic control of nuclear behavior during meiotic maturation of frog oocytes Journal of Experimental Zoology 177 129-146

Moor RM, Osborn JC, Cran DG and Walters DE (1981) Selective effect of gonadotrophins on cell coupling, nuclear maturation and protein synthesis in mammalian oocytes Journal of Embryology and Experimental Morphology 61 $347-365$

Nagai T, Takahashi T, Masuda H, Shioya Y, Kuwayama M, Fukushima M, Iwasaki S and Hanada A (1988) In vitro fertilization of pig oocytes by frozen boar spermatozoa Journal of Reproduction and Fertility 84 585-591

Nagai T, Ding J and Moor RM (1993) Effect of follicle cells and steroidogenesis on maturation and fertilization in vitro of pig oocytes Molecular Reproduction and Development 266 146-151

Naito K and Toyoda Y (1991) Fluctuation of histone H1 kinase activity during meiotic maturation in porcine oocytes Journal of Reproduction and Fertility 93 $467-473$

Naito K, Daen FP and Toyoda Y (1992) Comparison of histone H1 kinase activity during meiotic maturation between two types of porcine oocytes matured in different media in vitro. Biology of Reproduction 47 43-47

Niwa K and Chang MC (1975) Fertilization of rat eggs in vitro at various times before and after ovulation with special reference to fertilization of ovarian oocytes matured in culture Journal of Reproduction and Fertility 43 435-451

Niwa K, Park CK and Okuda K (1991) Penetration in vitro of bovine oocytes during maturation by frozen-thawed spermatozoa Journal of Reproduction and Fertility 91 329-336
Overstreet JW and Bedford JM (1974) Comparison of the penetrability of the egg vestments in follicular oocytes, unfertilized and fertilized ova of the rabbit Developmental Biology 41 185-192

Overstreet JW and Hembree WC (1976) Penetration of the zona pellucida of non-living human oocytes by human spermatozoa in vitro. Fertility and Sterility $27815-831$

Overstreet JW, Yanagimachi R, Katz DF, Hayashi K and Hanson FW (1980) Penetration of human spermatozoa into the human zona pellucida and the zona-free hamster egg: a study of fertile donors and infertile patients Fertility and Sterility 33 534-542

Polanski Z (1995) Activation of in vitro matured mouse oocytes arrested at first or second meiotic metaphase International Journal of Developmental Biology 39 $1015-1020$

Sagata N, Watanabe N, Vande Woude GF and Ikawa Y (1989) The c-mos proto-oncogene product is a cytostatic factor responsible for meiotic arrest in vertebrate eggs Nature 342 512-518

Snedecor GW and Cochran WG (1967) Statistical Methods Sixth Edition pp 327-329 The Iowa State University Press, lowa

Swann K (1990) A cytosolic sperm factor stimulates repetitive calcium increases and mimics fertilization in hamster eggs Development 110 1295-1302

Usui $\mathbf{N}$ and Yanagimachi R (1976) Behavior of hamster sperm nuclei incorporated into eggs at various stages of maturation, fertilization, and early development Journal of Ultrastructure Research 57 276-288

Wang WH and Niwa K (1997) Transformation of sperm nuclei into metaphase chromosomes in maturing pig oocytes penetrated in vitro. Zygote 5 183-191

Wang WH, Uchida M and Niwa K (1992) Effects of follicle cells on in vitro penetration of pig oocytes by cryopreserved, ejaculated spermatozoa Journal of Reproduction and Development 38 125-131

Wang WH, Abeydeera LR, Okuda K and Niwa K (1994) Penetration of porcine oocytes dring maturation in vitro by cryopreserved ejaculated spermatozoa Biology of Reproduction 50 510-515

Yoshida M (1993) Role of glutathione in the maturation and fertilization of pig oocytes in vitro. Molecular Reproduction and Development 35 76-81 